\title{
Standards of hygiene for ultrasound-guided core cut biopsies of the breast
}

\section{Hygienestandards bei der ultraschallgesteuerten Stanzbiopsie an der Mamma}

Authors

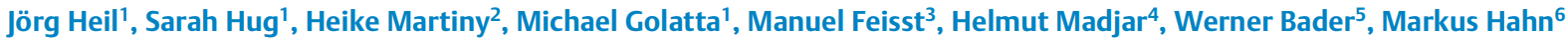

Affiliations

1 Obstetrics and Gynecology, University-Hospital, Heidelberg, Germany

2 Technical Hygiene, Charité, Berlin, Germany

3 Institute of Medical Biometry and Informatics, University of Heidelberg, Germany

4 Gynäkologie, DKD-HELIOS-Klinik Wiesbaden, Germany

5 Frauenklinik Nordstadtkrankenhaus, Krankenhaus Region Hannover, Germany

6 Frauenklinik, Universitätsklinik Tübingen, Tübingen, Germany

Key words

breast ultrasound, core cut biopsy, hygiene, infection

received 11.03 .2018

accepted 09.07.2018

Bibliography

DOI https://doi.org/10.1055/a-0667-7898

Published online: September 25, 2018

Ultraschall in Med 2018; 39: 636-641

(c) Georg Thieme Verlag KG, Stuttgart · New York

ISSN 0172-4614

Correspondence

Dr. Jörg Heil

Obstetrica and Gynecology, University-Hospital, Heidelberg,

INF 440, 69120 Heidelberg, Germany

Tel.: ++49/6221/5638555

joerg.heil@med.uni-heidelberg.de

\section{ABSTRACT}

Purpose The aim was to obtain an overview of the hygiene measures undertaken during ultrasound guided core cut biopsies of the breast by experts certified by the German Society for Ultrasound in Medicine in order to derive recommendations for clinical routine, taking into account the available literature and the lack of evidence based guidelines.

Materials and Methods A survey was conducted with all members of the levels I to III of the breast ultrasound working group of the German Society for Ultrasound in Medicine. The estimation of the risk of infection after a core cut biopsy of the breast was asked for as well as the hygiene measures undertaken in practice to avoid infection.

Results The risk of infection after a core cut biopsy of the breast was estimated to be one per thousand (median value). The most commonly performed hygiene measures were a spray, wipe, spray desinfection (98.1\%) and the use of sterile gloves (54.7\%).

Conclusion Due to the very low risk of infection we recommend the routine use of gloves and an adequate skin disinfection. Contact of the transducer or of an unsterile contact medium with the biopsy needle is considered highly unlikely und should be avoided.

\section{ZUSAMMENFASSUNG}

Ziel Ziel dieser Arbeit war es, eine Übersicht von über die Deutsche Gesellschaft für Ultraschall in der Medizin zertifizierten Experten über durchgeführte Hygienemaßnahmen bei der ultraschallgeführten Stanzbiopsie der Mamma zu erhalten, um daraus in Kenntnis der vorliegenden Literatur und mangels evidenzbasierter Leitlinien aktuelle Handlungsempfehlungen für die klinische Routine abzuleiten.

Material und Methode Es wurde eine Umfrage unter allen Mitgliedern der Stufe I-III des Arbeitskreises Mamma-Sonografie der Deutschen Gesellschaft für Ultraschall in der Medizin durchgeführt. Erfragt wurde die Einschätzung eines Infektionsrisikos bei der Stanzbiopsie der Mamma und welche Hygienemaßnahmen in der Praxis durchgeführt werden, um eine Infektion zu vermeiden.

Ergebnisse Das Risiko für eine Infektion nach einer Stanzbiopsie der Mamma wurde im Median auf 1 Promille geschätzt. Die häufigsten durchgeführten Hygienemaßnahmen waren eine Sprüh-Wisch-Sprüh-Desinfektion $(98,1 \%)$ und die Verwendung steriler Handschuhe (54,7\%).

Schlussfolgerungen Aufgrund des sehr geringen Infektionsrisikos empfehlen wir, in der Routine Handschuhe zu nutzen und eine adäquate Hautdesinfektion durchzuführen. Der Kontakt des Schallkopfes oder eines unsterilen Kontaktmediums mit der Biopsie-Nadel wird als äußerst unwahrscheinlich eingeschätzt und sollte vermieden werden. 


\section{Introduction}

Core-cut biopsy is the most common minimally-invasive procedure to obtain tissue in the course of clarifying unclear findings in the breast and can generally be guided via ultrasound under local anesthesia [1 - 5]. There is no specific evidence for meaningful hygienic measures for breast core-cut biopsies; likewise there are few evidence-based guidelines in this regard.

This work is intended to clarify which hygienic measures are currently used in the clinical routine when performing a mammary core biopsy.

The basic prerequisite for a hygienically acceptable core-cut biopsy is adequate cleaning and disinfection of the ultrasonic head according to the manufacturer's instructions. If this device is used on intact skin, it is rated as an uncritical medical product by the Commission for Hospital Hygiene and Infection Prevention (KRINKO) at the Robert Koch Institute as well as the German Federal Institute for Drugs and Medical Devices [6]. Uncritical medical devices must be cleaned and disinfected according to the manufacturer's instructions [6]. For ultrasound-guided transcutaneous biopsies requiring a sound-conductance medium at the point of biopsy, alcohol-based disinfecting agent or sterile ultrasound gel should also be used [7], since pathogens cannot be transferred via sterile ultrasound gel [8, 9]. In the German Federal Health Gazette, KRINKO has issued further recommendations on hygiene measures for punctures and injections [7]. Such interventions are classified into four risk groups (see $>$ Table 1). However, breast core-cut biopsy is not explicitly mentioned as a procedure.

KRINKO classifies various injections and punctures into the following risk groups: a venous blood sample, for example, into Group 1, a diagnostic pleural or ascites puncture into Group 2, organ punctures (for example, the liver) into Group 3 and the installation of a pleural drainage (Bülau method) into Group 4. Depending on the risk group, recommendations are made as to which hygienic measures should be performed.

No special measures are required for Group 1 procedures; for Group 2 procedures, sterile swabs or adequate spray disinfection and sometimes sterile gloves, sterile mouth and nose protection are recommended, but not for all procedures in this group. KRINKO also notes that ultrasound-guided interventions which may involve contact of the transducer head with the puncture site or biopsy needle require the use of a sterile cover for the transducer [7].

In its guidelines, the European Federation of Societies for Ultrasound in Medicine and Biology (EFSUMB) distinguishes between minor and major interventions. The guideline focuses on abdominal interventions and does not specifically address breast core-cut biopsies. For so-called minor interventions, normal hand and skin disinfection, lab coat and sterile gloves suffice. For major interventions or those with an increased infection risk, a mask and head covering should be used. In addition, skin disinfection similar to that for surgery is recommended. Sterile transducer covers and sterile ultrasound gel should be used for all interventions, and single-use biopsy materials are recommended [10].

The primary literature provides little data regarding infectious complications after a breast core-cut biopsy. A large retrospective analysis examined nearly 13000 cases for postinterventional infections after mammary biopsy performed without a transducer
- Table 1 Injection and puncture risk groups according to KRINKO, modified according to [7].

\begin{tabular}{|l|l|}
\hline risk & criteria \\
\hline 1 & $\begin{array}{l}\text { Simple puncture procedure } \\
\text { and } \\
\text { Low risk of puncture-related infection }\end{array}$ \\
\hline 2 & $\begin{array}{l}\text { Simple puncture procedure } \\
\text { and } \\
\text { Low infection risk, but severe subsequent infection } \\
\text { documented in the literature with rare case of infection } \\
\text { and } \\
\text { No need for interim storage of sterile puncture equipment }\end{array}$ \\
\hline 3 & $\begin{array}{l}\text { Puncture of organs or body cavities } \\
\text { or } \\
\text { Complex puncture procedure necessitating interim storage } \\
\text { of sterile puncture equipment, with or without assistant }\end{array}$ \\
\hline $\begin{array}{l}\text { Complex puncture procedure necessitating interim storage } \\
\text { of sterile puncture equipment and sterile preparation by an } \\
\text { assistant } \\
\text { and/or } \\
\text { Introduction of catheters or foreign material into body } \\
\text { cavities or deep tissue spaces (e. g. ventricle catheters, } \\
\text { peridural catheters) }\end{array}$ \\
\hline 4 & \begin{tabular}{l} 
and \\
\hline 3
\end{tabular} \\
\hline
\end{tabular}

cover. The biopsied region was sterile and sterile gel was used. Infections were documented in $0.11 \%$ of cases. All infections were superficial and were treated with an oral antibiotic. No sepsis was documented; likewise there were no invasive follow-ups or hospitalizations resulting from infectious complications after a breast core-cut biopsy [11]. An older retrospective analysis reported only superficial infection in 1836 biopsies (corresponding to $0.05 \%$ ) [1]. A 2010 review comparing the effectiveness of core needle biopsies with that of open surgical biopsies indicated $0.15 \%$ infections requiring treatment after core needle biopsies, although infections were not prospectively recorded [12]. Based on this data, the risk of infection after a core-cut biopsy of the breast can be classified as low.

Since neither the recommendations of KRINKO nor the EFSUMB guidelines deal specifically with breast core-cut biopsy, the aim of this study was to query the clinical routine of a large, representative cohort of physicians performing sonographicallyguided breast core-cut biopsies in order to make practical recommendations for action in light of the literature outlined above for the implementation of breast core needle biopsies.

\section{Methods}

In order to maintain the estimate (level of evidence 5), between May and July 2017 an online survey was performed of all members of the Breast Sonography working group of the German Society for Ultrasound in Medicine (DEGUM). All members of DEGUM levels I to III (increasing qualification levels) were invited by e-mail and received a one-time reminder. Participation was anonymous via a link and took about three minutes. 
The following questions were posed to the participants:

1. What is your certification status?

2. How many core-cut biopsies have you personally performed in the last 5 years?

3. KRINKO (Commission for Hospital Hygiene and Infection Prevention of the Robert Koch Institute) assigns interventions to the following risk groups: to which risk group would you assign sonographically-guided core-cut biopsy? Note: see

- Table 1, the definitions of the risk groups were previously made familiar to the participants in this question.

4. In your experience, how likely is it for an experienced physician (> 50 biopsies) to contact the transducer head with the trocar or the biopsy needle during a sonographically-guided core-cut biopsy?

5. In your experience, how high is the rate of infections requiring treatment per 1000 sonographically-guided core-cut biopsies?

6. Do you use sterile gloves for sonographically-guided core-cut biopsies?

7. Do you use a face mask for sonographically-guided core-cut biopsies?

8. Do you adequately disinfect the skin (spray-wipe-spray disinfection) prior to performing a sonographically-guided corecut biopsy?

9. Do you cover the patient in the area of the breast with sterile cloths prior to a core-cut biopsy

10. Do you use a sterile wrapped transducer head for sonographically-guided core-cut biopsies?

11. In the majority of biopsies do you use single-use or multi-use systems?

12. If you utilize reusable systems, what hygienic treatment of the device do you regularly perform?

\section{Statistical Analysis}

Discrete answers and characteristics were given in absolute and relative frequencies, median and quartile were calculated for numerical responses.

How many of the mentioned hygiene measures (sterile gloves, mask, skin disinfection, sterile cloth, sterile wrapped transducer head) used by the examiners was also evaluated. The result was a "hygiene score" rated from 1 to 5 , based on the following assessment: The participant received one point for each "Yes" response for questions 6 - 10; thus at least 0 points to a maximum of 5 were given. A higher score corresponds to a higher number of employed hygiene measures.

Group comparisons among the DEGUM levels were calculated for questions $2-5$ and the hygiene score. In addition, the hygiene score was examined for differences as a function of risk assessment (Question 3).

For the group comparisons, chi-square tests were calculated between discrete answers; due to non-normal distribution variables, non-parametric Kruskal-Wallis tests were performed.

P-values less than 0.05 were descriptively considered significant.

\section{Development of conclusions from the results}

After the literature review and evaluation of the survey, the results were discussed in a teleconference among all Level III members of the Breast Sonography working group of DEGUM, and there was a consensus regarding the recommendations below for the application of hygiene standards for sonographically-guided core-cut biopsy of the breast.

\section{Results}

The participation rate was $41.6 \%$ (277/666). Invited were 33 members of Level III including Level II instructors (participation rate $78.8 \%$ ), joined by 178 Level II members (participation rate $60.1 \%$ ) as well as 455 Level I members (participation rate $29.5 \%$ ).

Ten participants did not complete the questionnaire and were excluded from the evaluation.

The results of the survey are shown summarized in $\mathbf{T}$ Table 2 .

134 of the participants (corresponding to $50.19 \%$ ) were members of DEGUM Level I, 107 (corresponding to $40.1 \%$ ) belonged to DEGUM Level II, 8 (corresponding to $3 \%$ ) were DEGUM Level II course instructors and 18 (corresponding to 6, 7\%) were members of DEGUM Level III. The median had carried out 300 corecut biopsies in the past 5 years.

Breast core-cut biopsy was assigned to Risk Group 1 according to KRINKO by $74.2 \%$.

The median likelihood for an experienced physician (> 50 biopsies) to contact the transducer head with the trocar or the biopsy needle in a sonographically-guided core-cut biopsy was indicated to be $2 \%$. The rate of infections requiring therapy after a core-cut biopsy was estimated at one per thousand.

The participants performed the following hygienic measures:

$54.7 \%$ of participants use sterile gloves for a biopsy; $1.9 \%$ use a mask. Spray-wipe-spray disinfection is performed by $98.1 \%$. $13.9 \%$ cover the breast with a sterile cloth, and $11.2 \%$ use a sterile transducer cover. $54.7 \%$ (corresponding to 146) employ reusable biopsy systems. Details can be found in $\mathbf{T a b l e} \mathbf{2}$.

The calculated hygiene score is shown in $>$ Table 3.

Only $1 \%$ of participants do not use any of the named hygienic measures. Most physicians performing biopsies utilize one or two hygienic measures, few utilize three or four of the identified measures.

Examiners belonging to DEGUM Level I consider core-cut biopsy to be a higher risk compared to members of Levels II and III, whereas Level II examiners see the lowest risk for this biopsy $(p=0.351)$. In addition, DEGUM Level I examiners on average use significantly more hygienic measures $(p=0.014)$, see $>$ Fig. 1,2 .

On average, participants belonging to higher DEGUM levels have performed significantly more core-cut biopsies $(p<0.001)$ and they tend to indicate a lower probability of contact between the transducer head with the biopsy needle $(p=0.1782)$ as well as the danger of infections requiring treatment $(p=0.003)$.

Participants assigning core-cut biopsy to Risk Group 1 according to KRINKO guidelines use significantly fewer hygienic measures (hygiene score: median =1.5; Q1 =1; Q3 = 2) compared to those assigning the procedure to Risk Group $2(\mathrm{M}=2 ; \mathrm{Q} 1=1$; $\mathrm{Q} 3=3)$ oder $3(\mathrm{M}=2$; $\mathrm{Q} 1=2 ; \mathrm{Q} 3=3)(\mathrm{p}<0.001)$. 
- Table 2 Survey results.

\begin{tabular}{|c|c|c|c|}
\hline question & response & $\begin{array}{l}\text { number / } \\
\text { median }\end{array}$ & percent (\%) / quartile (Q1;Q3) \\
\hline \multicolumn{4}{|c|}{ question 1 participant certification status } \\
\hline & DEGUM I & 134 & $50.19 \%$ \\
\hline & DEGUM II & 107 & $40.07 \%$ \\
\hline & $\begin{array}{l}\text { DEGUM II instructors and } \\
\text { DEGUM III }\end{array}$ & 26 & $9.74 \%$ \\
\hline \multicolumn{4}{|c|}{ question 2 number of core-cut biopsies / 5 years } \\
\hline & & 300 & $150 ; 600$ \\
\hline \multicolumn{4}{|c|}{ question 3 KRINKO risk group } \\
\hline & group 1 & 198 & $74.16 \%$ \\
\hline & group 2 & 58 & $21.72 \%$ \\
\hline & group 3 & 11 & $4.12 \%$ \\
\hline \multicolumn{4}{|c|}{ question 4 contact of transducer head / biopsy needle } \\
\hline & & $2 \%$ & $0 \% ; 5 \%$ \\
\hline \multicolumn{4}{|c|}{ question 5 rate of infection / 1000 biopsies } \\
\hline & & 1 & $0 ; 2$ \\
\hline \multicolumn{4}{|c|}{ question 6 sterile gloves } \\
\hline & yes & 146 & $54.68 \%$ \\
\hline & no & 121 & $45.32 \%$ \\
\hline \multicolumn{4}{|c|}{ question 7 face mask } \\
\hline & yes & 5 & $1.87 \%$ \\
\hline & no & 262 & $98.13 \%$ \\
\hline \multicolumn{4}{|c|}{ question 8 spray-wipe-spray disinfection } \\
\hline & yes & 262 & $98.13 \%$ \\
\hline & no & 5 & $1.87 \%$ \\
\hline \multicolumn{4}{|c|}{ question 9 sterile cloths } \\
\hline & yes & 37 & $13.86 \%$ \\
\hline & no & 230 & $86.14 \%$ \\
\hline \multicolumn{4}{|c|}{ question 10 sterile transducer cover } \\
\hline & yes & 30 & $11.24 \%$ \\
\hline & no & 237 & $88.76 \%$ \\
\hline \multicolumn{4}{|c|}{ question 11 multi-use systems } \\
\hline & yes & 146 & $54.68 \%$ \\
\hline & no & 121 & $45.32 \%$ \\
\hline \multicolumn{4}{|c|}{ question 12 preparation (question answered by 146 respondents, see question 11: multi-use systems = Yes = 146) } \\
\hline & disinfection & 102 & $70 \%$ \\
\hline & sterilization & 54 & $37 \%$ \\
\hline & washing & 41 & $28 \%$ \\
\hline
\end{tabular}

\section{Discussion}

Several years ago, the multi-level concept of DEGUM created a quality-assured performance standard for sonography optimally suited for the recording of empirical values for a hygiene standard for core-cut biopsies of the breast. Overall, almost $42 \%$ of all cer- tified members of the Breast Sonography working group, including more than $60 \%$ and $79 \%$ of DEGUM Levels II and III respectively, including II course instructors, participated in the survey. The high participation rate of the latter's highly-qualified membership levels especially underscores the importance of the topic and underpins the informative value of the survey. 
- Table 3 Hygiene score Number of questions 6 - 10 answered with "Yes".

\begin{tabular}{|l|r|r|}
\hline hygiene score & number & percent (\%) \\
\hline 0 & 3 & $1 \%$ \\
\hline 1 & 113 & $42 \%$ \\
\hline 2 & 100 & $37 \%$ \\
\hline 3 & 38 & $14 \%$ \\
\hline 4 & 12 & $4 \%$ \\
\hline 5 & 1 & $0 \%$ \\
\hline
\end{tabular}

It seems plausible that experienced examiners assess the risk of core-cut biopsy rather low, since they have performed significantly more biopsies and tend to indicate a lower probability of contact between the transducer head with the biopsy needle as well as the risk of infections requiring treatment. This also explains the lower hygiene score in these groups.

The majority of the participants classify the core-cut biopsy of the breast into Risk Group 1, analogous to the example of a blood draw, which is reflected in the hygienic measures used. Most practitioners perform a spray-wipe-spray disinfection procedure. A narrow majority also use sterile gloves for the biopsy. Both of these are quick and comparatively simple to perform measures. This is probably also an explanation for the fact that sterile gloves are often used, although a clear majority of the participants assign core-cut biopsy to Risk Group 1.

Even if one quarter of core-cut biopsies of the breast are classified into Risk Groups 2 or 3, the risk of infection requiring treatment as a clinically significant complication is estimated to be very low with a median of one per thousand cases. This assessment is essentially consistent with the available empirical data $[1,11,12]$. However, since these are retrospective data, the hygienic measures carried out are often not fully documented. It should also be critically examined whether all infections have been documented were and known to the physician performing the biopsy. However, it seems probable that patients with severe infections would seek treatment from that physician, although there is no evidence to support this hypothesis. In the analysis by Reisenauer et al. telephone interviews querying regarding possible symptoms were conducted over a period of 9 years 48 hours post-biopsy. These interviews were discontinued due to the very low complication rate [11].

The extent to which an infection requiring treatment can actually be avoided by the aforementioned hygiene measures also remains speculative, since infectious agents could also penetrate via the puncture site after the intervention.

The KRINKO risk groups do not include core-cut biopsy of the breast in the risk groups, thus required hygienic measures cannot be directly derived from the KRINKO recommendations. The majority of participants assign the breast core-cut biopsy to Risk Group 1, which seems plausible in this respect, since a breast biopsy is a cutaneous appendage if performed correctly, a superficial intervention without opening a body cavity (such as in the

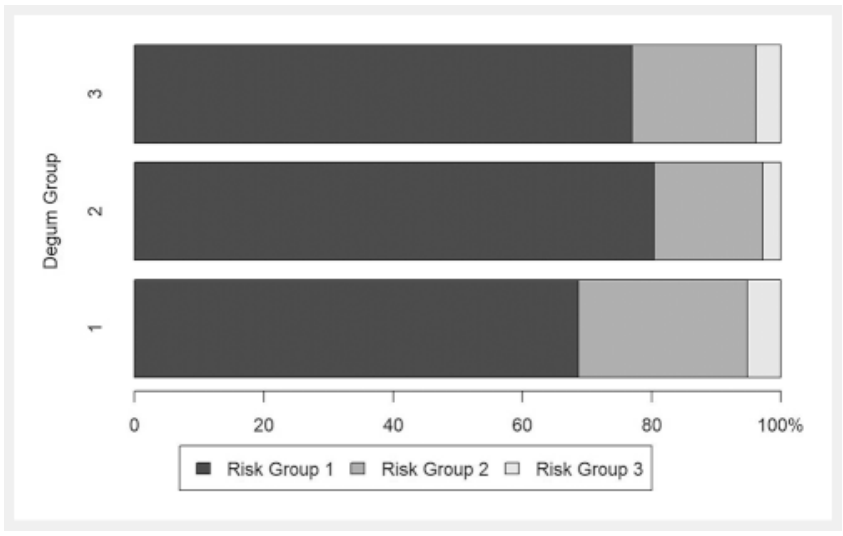

- Fig. 1 Assignment to risk groups broken down by DEGUM level.

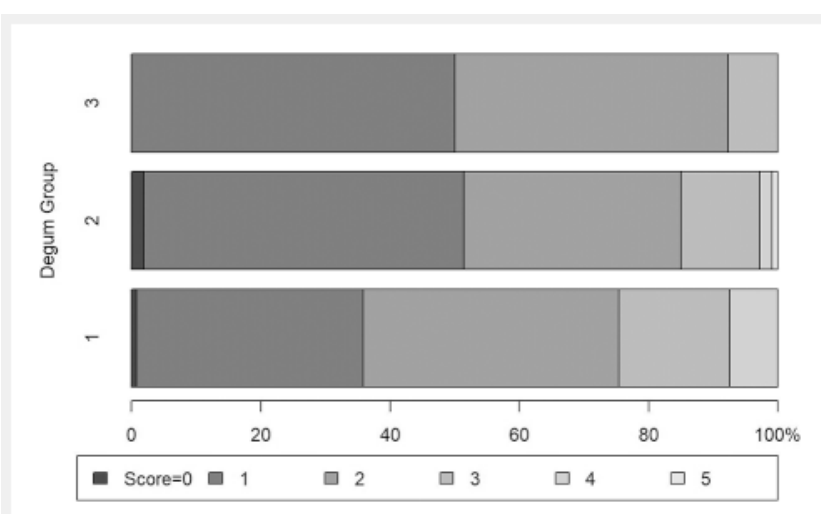

- Fig. 2 Hygiene score broken down by DEGUM level.

case of pleural or ascites puncture). This is distinguishing criterion for KRINKO risk classification [7].

However, the literature also documents severe complications after breast core-cut biopsy. Thus Roque et al. report a necrotizing infection after core-cut biopsy confirming breast cancer in an 80year-old patient. No information is given on the procedure and hygienic measures taken during the biopsy nor regarding the pathogen [13]. Kasprowicz et al. describe the case of a 48-year-old female patient who, after core-needle biopsy to confirm a phyllodes tumor, exhibited chronic mastitis without pathogen detection for months, so that the patient finally decided on bilateral mastectomy [14]. Flandrin et al. report on necrotizing fasciitis after a breast biopsy [15]. Since the aspect "serious infection consequences documented in the literature in the (rare) occurrence of an infection" is a definition aspect of Risk Group 2, core-cut biopsy could thus be at most ascribed to that risk group; we consider this to be inadequate due to the extremely rare onset of infection and the much rarer occurrence of serious infection consequences.

Taking into account the available evidence, guidelines and the survey of experts, it appears to be sensible to perform sufficient skin disinfection in order to further minimize the overall low risk of infection as far as possible. Assuming that infections after breast core-cut biopsy occur only in the low occurrence per thou- 
sand range, the question arises which other measures beyond that are regularly justified in order to avoid an infection. A sterile transducer cover, for example, only questionably reduces the probability of infection. Thus Reisenaur et al. indicate the probability of infection at only $0.11 \%$, even after biopsies performed without a transducer cover [11]. The median probability of contact of the transducer head with the biopsy needle is estimated by the participants of this survey to be only $2 \%$. The use of a cover complicates the biopsy process and unnecessarily consumes human and material resources. According to KRINKO, this would only be necessary if the transducer head touches the puncture site or comes into contact with the puncture needle [7].

Furthermore, breast infection is usually uncomplicated and treated with oral antibiotics, except for isolated cases reported in the literature.

In summary, it should be noted that as required by the KRINKO and stated in $\S 36$ of the Infection Protection Act, each institution must create a hygiene plan for the performance of interventions [16]. It should also be pointed out that the use of reusable systems in biopsy is only permitted if they are handled according to the manufacturer's instructions using a validated procedure [6]. With regard to the preparation of the ultrasound head, the "DEGUM recommendations for hygiene in sonography and endosonografy" must be observed [17].

Based on the available data analysis of a survey of experts of the Breast Sonografy working group of DEGUM and utilizing knowledge of the empirical evidence, this working group approved the following conclusions for sonografically-guided breast core-cut biopsy taking in account of the general KRINKO recommendations:

- Adequate skin disinfection either as a spray disinfectant or as a spray-wipe-spray disinfection using a sterile swab

- Hygienic hand disinfection and use of gloves

- Adequate cleaning and disinfection of the ultrasound head

- Use of a sterile contact medium

- A sterile transducer cover is usually not required, as contact of the transducer head with the puncture site or the biopsy needle and resulting infection is extremely unlikely.

This recommendation was discussed and approved by all Level III members of the Breast Sonografy working group of DEGUM. Concerning the choice of gloves, no consensus could be reached due to ambiguous survey results and lack of data, so that no differentiated recommendation can be made, and this point must remain open.

\section{Conflict of Interest}

The authors declare that they have no conflict of interest.

\section{References}

[1] Meyer JE, Smith DN, Lester SC et al. Large-core needle biopsy of nonpalpable breast lesions. Jama 1999; 281: 1638-1641

[2] Sauer G, Deissler H, Strunz K et al. Ultrasound-guided large-core needle biopsies of breast lesions: analysis of 962 cases to determine the number of samples for reliable tumour classification. British journal of cancer 2005; 92: 231 -235. doi:10.1038/sj.bjc.6602303

[3] Verkooijen HM, Peeters PH, Buskens E et al. Diagnostic accuracy of largecore needle biopsy for nonpalpable breast disease: a meta-analysis. British journal of cancer 2000; 82: 1017-1021. doi:10.1054/ bjoc.1999.1036

[4] Smith DN, Rosenfield DarlingML, Meyer JE et al. The utility of ultrasonografically guided large-core needle biopsy: results from 500 consecutive breast biopsies. Journal of ultrasound in medicine : official journal of the American Institute of Ultrasound in Medicine 2001; 20: $43-49$

[5] Liberman L, Ernberg LA, Heerdt A et al. Palpable breast masses: is there a role for percutaneous imaging-guided core biopsy? American journal of roentgenology 2000; 175: 779-787. doi:10.2214/ajr.175.3.1750779

[6] KRINKO. Anforderungen an die Hygiene bei der Aufbereitung von Medizinprodukten. Bundesgesundheitsbl 2012; 55: 1244-1310

[7] KRINKO. Anforderungen an die Hygiene bei Punktionen und Injektionen. Bundesgesundheitsbl 2011; 54: 1135-1144

[8] Oleszkowicz SC, Chittick P, Russo V et al. Infections associated with use of ultrasound transmission gel: proposed guidelines to minimize risk. Infection control and hospital epidemiology 2012; 33: 1235-1237. doi:10.1086/668430

[9] Provenzano DA, Liebert MA, Steen B et al. Investigation of current infection-control practices for ultrasound coupling gel: a survey, microbiological analysis, and examination of practice patterns. Regional anesthesia and pain medicine 2013; 38: 415-424. doi:10.1097/AAP.0b013e3182a0e12f

[10] Lorentzen T, Nolsoe CP, Ewertsen C et al. EFSUMB Guidelines on Interventional Ultrasound (INVUS), Part I. General Aspects (long Version). Ultraschall in der Medizin 2015; 36: E1 - 14. doi:10.1055/s-00351553593

[11] Reisenauer C, Fazzio RT, Hesley G. JOURNAL CLUB: Ultrasound-Guided Breast Interventions: Low Incidence of Infectious Complications With Use of an Uncovered Probe. American journal of roentgenology 2017; 208: 1147-1153. doi:10.2214/Am J Roentgenol.16.16440

[12] Bruening W, Fontanarosa J, Tipton K et al. Systematic review: comparative effectiveness of core-needle and open surgical biopsy to diagnose breast lesions. Annals of internal medicine 2010; 152: 238-246. doi:10.7326/0003-4819-152-1-201001050-00190

[13] Roque DR, MacLaughlan S, Tejada-Berges T. Necrotizing infection of the breast after core needle biopsy. The breast journal 2013; 19: 201 - 202. doi:10.1111/tbj.12088

[14] Kasprowicz N, Bauerschmitz G], Schonherr A et al. Recurrent Mastitis after Core Needle Biopsy: Case Report of an Unusual Complication after Core Needle Biopsy of a Phyllodes Tumor. Breast care 2012; 7: 240 - 244. doi:10.1159/000339689

[15] Flandrin A, Rouleau C, Azar CC et al. First report of a necrotising fasciitis of the breast following a core needle biopsy. The breast journal 2009; 15: 199-201. doi:10.1111/j.1524-4741.2009.00697.x

[16] Infektionssschutzgesetz. https://www.gesetze-im-internet.de/ifsg/ Letzter Zugriff 11.03.2018

[17] Mueller T et al. DEGUM-Empfehlungen zur Hygiene in Sonografie und Endosonografie. Ultraschall in der Medizin, in press 
